\title{
A STUDY ON BEHAVIOR OF TUNNEL IN SOFT SOIL CONDITIONS UNDER INFLUENCE OF EARTHQUAKES IN HO CHI MINH CITY
}

\author{
NGUYEN QUANG DUNG ${ }^{(1)}$, LE BAO QUOC ${ }^{(2)}$, NGUYEN DUC TAM ${ }^{(3)}$ \\ (I) Department of Civil Engineering, Industrial University of Ho Chi Minh City, \\ (2) Mien Tay Construction University, \\ (3) University of Transport and Communications - Campus in Ho Chi Minh City; \\ nguyenquangdung@iuh.edu.vn,quocvn21@yahoo.com,ndtam@utc2.edu.vn
}

\begin{abstract}
Due to economic development and traffic congestion constraints, HCM City has implemented urban railways since 2007 and is currently constructing the underground metro line No 01. So far, general constructions and tunnel in particular in Vietnam is a complex issue, especially in the specific soft soil conditions of Ho Chi Minh City. In order to study the behavior of the tunnel during the earthquake, this paper compares an Imposed Seismic Ground Deformation method (ISGD) and the acceleration diagram method in calculating the tunnel affected by the earthquake in soft soil of the area of Ho Chi Minh city.

Keywords: Seismic analysis, underground structure, Imposed Seismic Ground Deformation, acceleration diagram, soft soil.
\end{abstract}

\section{INTRODUCTION}

The Ho Chi Minh city has the complicated geology that the depth of soft soil is distributed in the range about 5 to 40 meters. Therefore, it is greatly ground displacements during the earthquake. When the earthquake occurs from the bedrock, seismic waves propagating upwards from bedrock in the ground may be cause deformation ground and underground constructions. In order to study the behevior between tunnel and soil, there are three approaches at present:

The analytical method is the most traditional approach, the soil platform was seperated from structure and replaced the equivalent earthquake load. Wang (1993) proposed this method and Penzien (1998) developed a method considering the deformation of turnel and soil platform. However, this method apply to calculate simply for one layer, isotropic, and uniformity.

The imposed seismic ground deformation method (ISGD) is the more improvement than the analytical method which is considered interaction of turnel and platform following Hamada(1984), using the springs to replace the interaction of structure and enviroment in model or inposing the deformation of soil platform for model calculations. The advantage of this approach compute simply but not considering the behavior of soil platform and turnel under earthquake load.

The Full dynamic method is considered the interaction of turnel and platform in details. This approach is current a new development based on the numerial method with suporting the computer technology that can solve the complex problems regarding the earthquake load conditions. However, the complex model calulation depends on the number of research parameters and the accuracy of dividing nets used in the calculation .

This study presents two calculating methods (The ISGD and full dynamic method) on the urban underground contructions in the soft soil with complicated geology in Ho Chi Minh city.

\section{CALCULATION OF EARTHQUAKE INFLUENCE ON THE TUNNEL USING IMPOSED SEISMIC GROUND DEFORMATION METHOD - ISGD.}

The influence of earthquake on tunnel and on-ground works is quite different. The loading capacity affects on underground constructions through the displacement of the ground while the loading capacity buiding on-ground by inertia force. According to ISDG method, with the seismic removes the ground environment leading to the imposing on the movement to the boundary in order to identify deformation of the structure. The way to identify the displacement of the ground is as follows: 
Deformation of ground on boundary is defined as:

$$
u_{i}=\frac{1}{\omega_{i}^{2}} \Gamma_{i} S_{e}\left\{\phi_{i}\right\}
$$

Where:

$\mathrm{S}_{\mathrm{e}}$ is the elastic response spectrum, it is determined based on Vietnamese standard TCVN 9386:2012; $\left\{\phi_{\mathrm{i}}\right\}$ is the amplitude oscillation of soil corresponding to the $\mathrm{i}^{\mathrm{t}}$ natural frequency of the circuit, and

$\Gamma_{\mathrm{i}}$ is the $\mathrm{i}^{\text {th }}$ coefficient of oscillation and is determined by the following the expression:

$$
\Gamma_{i}=\left\{\phi_{i}\right\}^{\mathrm{T}}[\mathrm{M}]\{\mathrm{d}\}
$$

Where:

$\{\mathrm{d}\}$ is the vector with $\mathrm{d}_{\mathrm{i}}=1$, used to transform the diagonal matrix $[\mathrm{M}]$ into a column matrix.

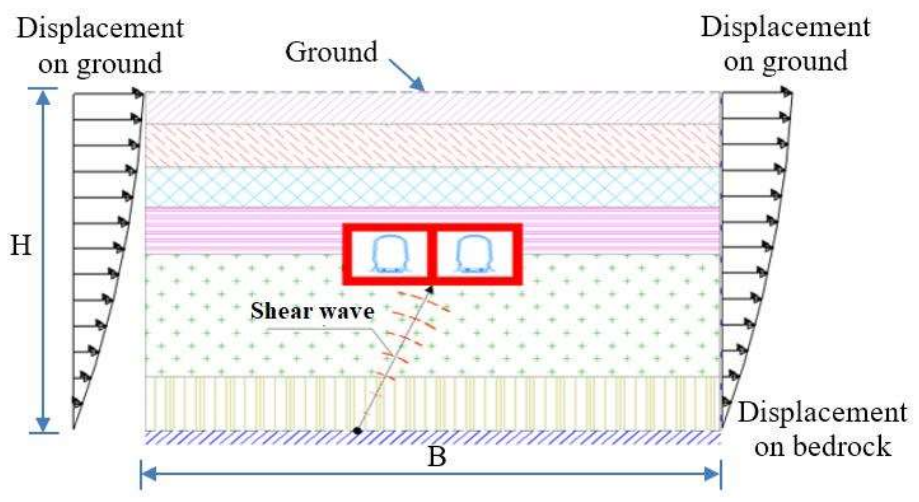

Figure 1. Model of Ground Deformation to boundary

The amplitude oscillate of soil $\left\{\phi_{i}\right\}$, determined from the equation (3):

$$
\left([\mathrm{K}]-\omega^{2}[\mathrm{M}]\right)\{\phi\}=0
$$

Where:

$\omega$ is natural frequency of circuit; $\omega^{2}=\lambda$ - the eigenvalues;

$\{\phi\}$ is the eigenvectors;

$[\mathrm{K}],[\mathrm{M}]$ are the stiffness matrix and mass matrix of the model.

To make the root for the equation (3), the determinant of the following matrix must be by 0 .

$$
\left|[\mathrm{K}]-\omega^{2}[\mathrm{M}]\right|=0
$$

Solving the equation (4) will find $\mathrm{N}$ value of $\omega^{2}$, it corresponds to the $\mathrm{N}$ mode of oscillatin of soil. And then replace into the equation (3) in order to find $[\phi]=\left[\begin{array}{lll}\phi_{1} & \ldots & \phi_{N}\end{array}\right]=\left[\begin{array}{ccc}\phi_{11} & \ldots & \phi_{1 N} \\ \ldots & \ldots & \ldots \\ \phi_{N 1} & \ldots & \phi_{N N}\end{array}\right]$. Because of solving an equation (4) with degree of $\omega^{2}$ is big, so it is so difficult in practice, the methods of cube resolution are usually applied for equation resolution (3) to find both values of $\omega^{2}$ and $[\phi]$.

The eigenvectors $\{\phi\}$ is orthogonal to the mass matrix according to the expression:

$$
\begin{gathered}
\{\phi\}^{T}[M] .\{\phi\}=1 \\
\text { thus }\{\phi\}^{T}[K] .\{\phi\}=\omega^{2}
\end{gathered}
$$

The methods are usually applied that are inversely iterative method, subspace iterative method and method of Lanczos. Deriving from the mathematical methods, the author build the calculation software based on the programming language Pascal named "Soil Column Vibration - SCV2015". The program can be used for calculating the deformation of ground in the case of earthquake and export the results of displacement, velocity and acceleration at the height of ground soil levels. 


\section{CALCULATION OF EARTHQUAKE INLUENCE ON THE TUNNEL USING THE ACCELERATION DIAGRAM - FULL DYNAMIC METHOD.}

Equation of motion differential of system under the effect of earthquake load [2]:

$$
[M]_{n}\{\ddot{u}\}_{n}+[C]_{n}\{\dot{u}\}_{n}+[K]_{n}\{u\}_{n}=\{F\}_{n}
$$

Where:

$\{\ddot{\mathrm{u}}\}_{\mathrm{n}},\{\dot{\mathrm{u}}\}_{\mathrm{n}},\{\mathrm{u}\}_{\mathrm{n}}$ are the displacement, velocity and acceleration vector of the $\mathrm{n}^{\text {th }}$ element;

$[\mathrm{M}]_{\mathrm{n}},[\mathrm{C}]_{\mathrm{n},}[\mathrm{K}]_{\mathrm{n}}$ are the mass, damping and stiffness matrices of the $\mathrm{n}^{\text {th }}$ element;

$\{\mathrm{F}\}_{\mathrm{n}}$ is the nodal load vector of $\mathrm{n}^{\text {th }}$ element;

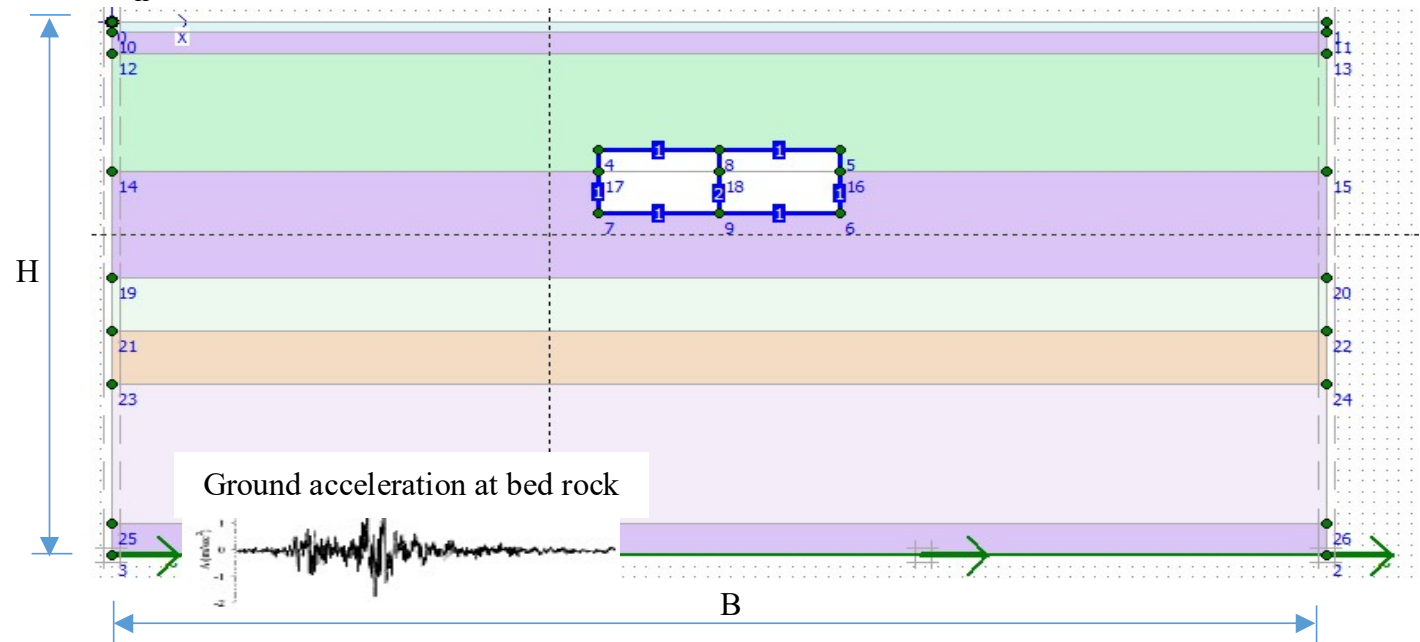

Figure 2. Model calculating of tunnel affected by earthquake by the acceleration diagram

The matrices of elements $[\mathrm{K}]_{\mathrm{n}},[\mathrm{M}]_{\mathrm{n}},\{\mathrm{F}\}_{\mathrm{n}}$ are built in the local coordinate system of elements. To build the full-system equations of motion, it is essential to change the equations of motion in the local coordinate system of elements into the global coordinate system of elements by the movement coordinate matrix and to use the direct stiffness methods to assemble the elements into the system then receive the fullsystem equations of motion [2].

$$
[\bar{M}]\}\{\ddot{u}\}+[\bar{C}]\{\dot{u}\}+[\bar{K}]\} u\}=\{\bar{F}\}
$$

Where:

$\{\ddot{\mathrm{u}}\},\{\dot{\mathrm{u}}\},\{\mathrm{u}\}$ are the displacement, velocity and acceleration vector of system;

$[\overline{\mathrm{M}}],[\overline{\mathrm{C}}],[\overline{\mathrm{K}}]$ are the mass, damping and stiffness matrices of the system in the coordinate system, and

$\{\overline{\mathrm{F}}\}_{\mathrm{n}}$ is the external load vector of system in the coordinate system;

The mass matrix $[\mathrm{M}]$ is determined by the mass matrix of soil ground, water and structure; The damping matrix $[\mathrm{C}]$ is difficult to be determined, especially in calculating a multi degree of freedom because the damping data depends on the vibration frequencies of the system at the any points. Hence, in dynamics calculation used the assumptions that the damping matrix $[\bar{C}]$ is the linear combination of the mass matrix $[\overline{\mathrm{M}}]$ and the stiffness matrix $[\overline{\mathrm{K}}]$ of the system by the two Rayleigh constants $\alpha_{\mathrm{R}}$ and $\beta_{\mathrm{R}}$ as follow [2]:

$$
[\overline{\mathrm{C}}]=\alpha_{\mathrm{R}}[\overline{\mathrm{M}}]+\beta_{\mathrm{R}}[\overline{\mathrm{K}}]
$$

The two Rayleigh constants are related to the $\mathrm{i}^{\text {th }}$ and $\mathrm{j}^{\text {th }}$ natural frequency of the vibration soil medium, $\omega_{\mathrm{i}}, \omega_{\mathrm{j}}$, These natural frequencies correspond to the damping ratios, $\xi_{\mathrm{i}}, \xi_{\mathrm{j}}$ : 


$$
\left\{\begin{array}{l}
\alpha_{R} \\
\beta_{R}
\end{array}\right\}=\left\{\begin{array}{l}
\frac{2\left(\xi_{i} \omega_{i}-\xi_{j} \omega_{j}\right)}{\omega_{j}^{2}-\omega_{i}^{2}} \omega_{i} \omega_{j} \\
\frac{2\left(\xi_{i} \omega_{i}-\xi_{j} \omega_{j}\right)}{\omega_{j}^{2}-\omega_{i}^{2}}
\end{array}\right\}
$$

Usually, the impact of natural high frequency of the vibration soil medium on the value of the damping ratio is negligible. Therefore, in calculation, the damping ratio may be considered the constant and depends on the two lowest natural high frequencies of the vibration soil medium.

$$
\left\{\begin{array}{l}
\alpha_{R} \\
\beta_{R}
\end{array}\right\}=\left\{\begin{array}{l}
\frac{2 \xi}{\omega_{1}+\omega_{2}} \omega_{1} \omega_{2} \\
\frac{2 \xi}{\omega_{1}+\omega_{2}}
\end{array}\right\}
$$

Besides, The two Rayleigh constants $\alpha_{R}, \beta_{R}$ may be determined in the simple method depending on the damping ratio $\xi$ as follows [5].

$$
\begin{gathered}
\alpha_{\mathrm{R}}=\frac{2}{3} \xi \text {, và } \beta_{\mathrm{R}}=\frac{1}{3} \xi \\
\text { with } \xi=\frac{\sum \eta_{\mathrm{i}} \mathrm{h}_{\mathrm{i}}}{\mathrm{H}}
\end{gathered}
$$

Where: $\eta_{i}$ is the damping ratio of $i^{\text {th }}$ soil layer, $h_{i}$ is the thickness of $i^{\text {th }}$ soil layer and $H$ is the total heigh of soil layer.

On the boundary of calculation model, there are some connections and after applying the boundary conditions into the system, the vectors and matrices of the system change to the following forms $[\overline{\mathrm{M}}] \rightarrow[\mathrm{M}]$, $[\overline{\mathrm{C}}] \rightarrow[\mathrm{C}],[\overline{\mathrm{K}}] \rightarrow[\mathrm{K}],\{\overline{\mathrm{R}}\}=\{\mathrm{R}\}$ và $\{\overline{\mathrm{u}}\}=\{\mathrm{u}\}$. The equation (8) becomes:

$$
[M]\{\ddot{u}\}+[C]\{\dot{u}\}+[K]\{u\}=\{F\}
$$

When the material behavior is elasticity, the damping matrix $[\mathrm{C}]$ and the stiffness matrix $[\mathrm{K}]$ only depend on the elastic module E and Poisson $v$ coefficient. Therefore, matrices and vectors in equation (14) do not change in all the calculating process. When the material behavior is inelasticity like as elastoplastic, visco-elastic and visco-plastic behavior...., the stress depends on deformation, deformation depends on displacement. Therefore the damping matrix $[\mathrm{C}]$ and the stiffness matrix $[\mathrm{K}]$ depend on the nodal displacement vector follow as $[K]=[K\{u\}],[C]=[C\{u\}]$.

In this case, the equation (14) will be rewritten as follows [2]:

$$
[M]\{\ddot{u}\}+[C\{u\}]\{\dot{u}\}+[K\{u\}]\{u\}=\{F\}
$$

When calculating the effects of earthquake by the acceleration diagram, the equation (15) becomes:

$$
[M]\} \hat{u}\}+[C\{u\}\}\{\dot{u}\}+[K\{u\}]\{u\}=[M]\{\ddot{u}\}_{g}
$$

Where: $\{\ddot{\mathrm{u}}\}_{\mathrm{g}}$ is the ground acceleration vector is made by earthquake on the bedrock.

Solving the equation of the structural system - the background (16) determines the displacement of the element's nodes and uses the relations of the finite element method to calculate the internal force, deformation and stress in each element. To solve the equation (16) using Newmark's direct integration method combined with the Newton-Raphson iterative method is more effective in terms of simplicity, stability and accuracy [2]. 


\section{NUMERICAL TRIAL ON COMPUTER}

\subsection{The ISGD Method}

Initial data: Calculate the displacement on the vertical boundary of the model due to the effect of onedimensional shear wave in a multi-layer environment with a depth of $\mathrm{H}=50 \mathrm{~m}$. The parameters of soil medium with multiple layers on bedrock are given in table 1 . The Ground acceleration at the roundabout Phu Lam -district 6 - Ho Chi Minh city (Follow the instruction of the standard TCVN 9386:2012) is $\mathrm{a}_{\mathrm{g}}=0,07 \mathrm{~g}$ [4] with elastic response spectrum for ground soil D class.

Table 1. Parameters of soil medium with multiple layers on bedrock

\begin{tabular}{|c|c|r|r|r|r|c|}
\hline \multirow{2}{*}{ Layers } & \multirow{2}{*}{$\begin{array}{c}\text { Thickness } \\
(\mathbf{m})\end{array}$} & \multicolumn{5}{|c|}{ Parameters } \\
\cline { 3 - 7 } & & $\begin{array}{c}\text { Heigh of } \\
\text { Subsoil } \mathbf{h}_{\mathbf{i}}(\mathbf{m})\end{array}$ & $\begin{array}{c}\text { Unit weight } \\
(\mathbf{k N})\end{array}$ & $\begin{array}{c}\text { Elastic modulus } \\
(\mathbf{k P a})\end{array}$ & $\begin{array}{c}\text { Poisson's } \\
\text { ratio }\end{array}$ & $\begin{array}{c}\text { Damping } \\
\text { ratio }\end{array}$ \\
\hline Layer F & 2 & 1 & 19,42 & 44.200 & 0,4 & 0,3 \\
\hline Layer 1b & 3,5 & 1 & 19,03 & 208.000 & 0,4 & 0,3 \\
\hline Layer 1 & 9,5 & 1 & 14,76 & 36.100 & 0,4 & 0,3 \\
\hline Layer 1b & 9,5 & 1 & 19,03 & 208.000 & 0,4 & 0,3 \\
\hline Layer 2 & 4,5 & 1 & 19,07 & 399.000 & 0,4 & 0,3 \\
\hline Layer 2a & 5,5 & 1 & 18,91 & 818.000 & 0,4 & 0,3 \\
\hline Layer 3 & 13 & 1 & 19,99 & 569.000 & 0,4 & 0,3 \\
\hline Layer 4 & 2,5 & 1 & 20,07 & 767.000 & 0,4 & 0,3 \\
\hline
\end{tabular}

Using the Soil Column Vibration - SCV 2015 V1.0 program to determine the velocity, acceleration and displacement corresponding to each location of the soil layer in the following figure 3 .
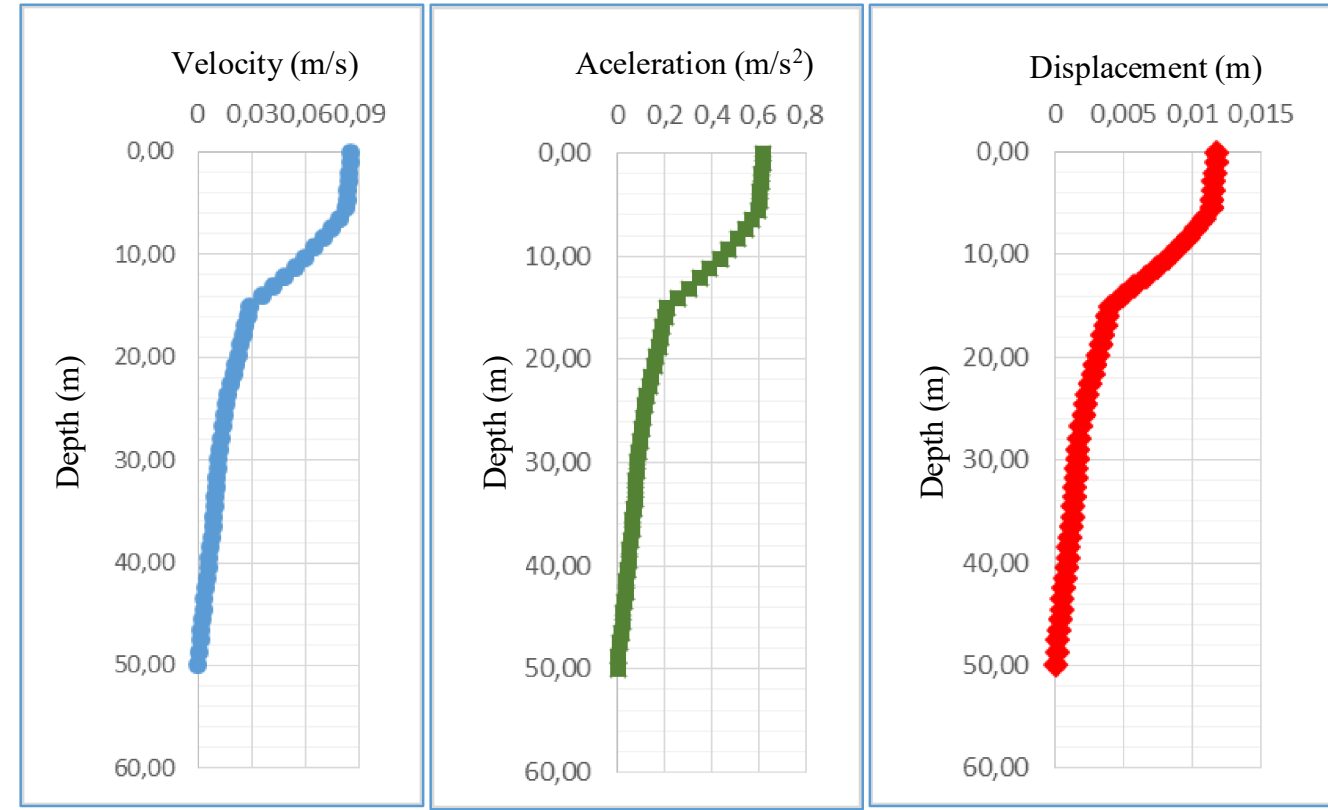

Figure 3. Graph of acceleration, velocity and displacement in depth of soil columns on hard ground from the SCV-2015 program.

Numerical modeling: Figure 4 show the 2D model of the rectangular underground structure placed in a multi-layer soil medium in Plaxis program. Displacement of the background was defined above (Figure 3 ) is placed on the boundary of a model to determine the deformation, internal force of the structure. When 
calculating, assumption that: Behavior of material tunnel is linear elastic; The soil medium is modeled as an elastoplastic, the mechanical and physical properties of the subsoil change in every layer but do not change in a layer; Displacement and deformation at any point of the structural - environmental system is minor.

The rectangle tunnel has $\mathrm{BxH}=20 \mathrm{mx} 6 \mathrm{~m}$, the depth of the top and bottom slab is $1 \mathrm{~m}$, depth of wall is $0,8 \mathrm{~m}$. The concrete of tunnel lining has $\mathrm{E}=3,5 \times 10^{7} \mathrm{kPa}$ and the Poisson's ratio $v=0,2$.

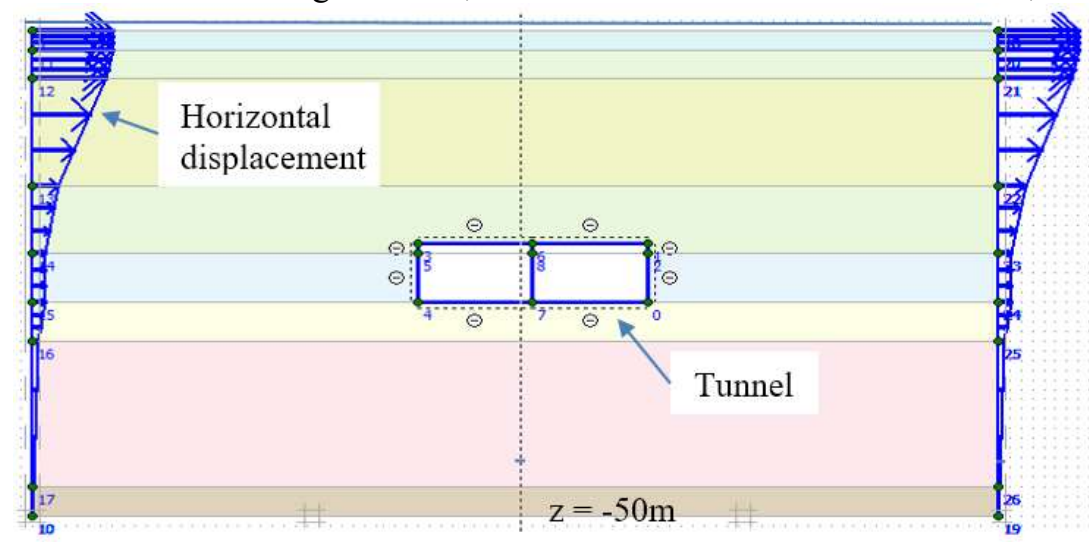

Figure 4. View of modeling in Plaxis

The results of the ISGD method: Based on input data and using Plaxis software version 2010.01 (code DP111208 - f12a2cfd - 6c8134e0), the internal forces - time diagram and maximum displacement of the lining was determined as shown in Figure 5 to Figure 8.

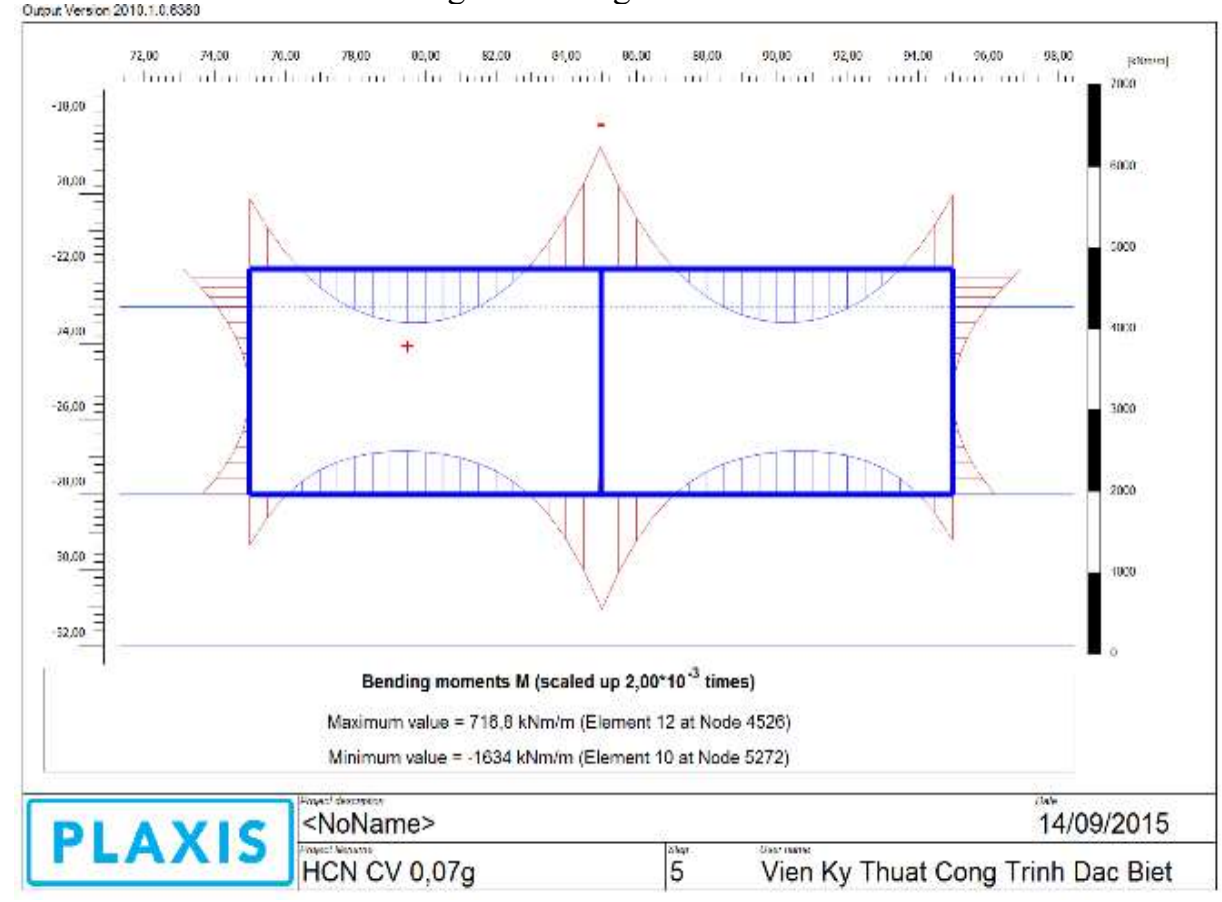

Figure 5. Bending moments of tunnel lining 
A STUDY ON BEHAVIOR OF TUNNEL IN SOFT SOIL CONDITIONS

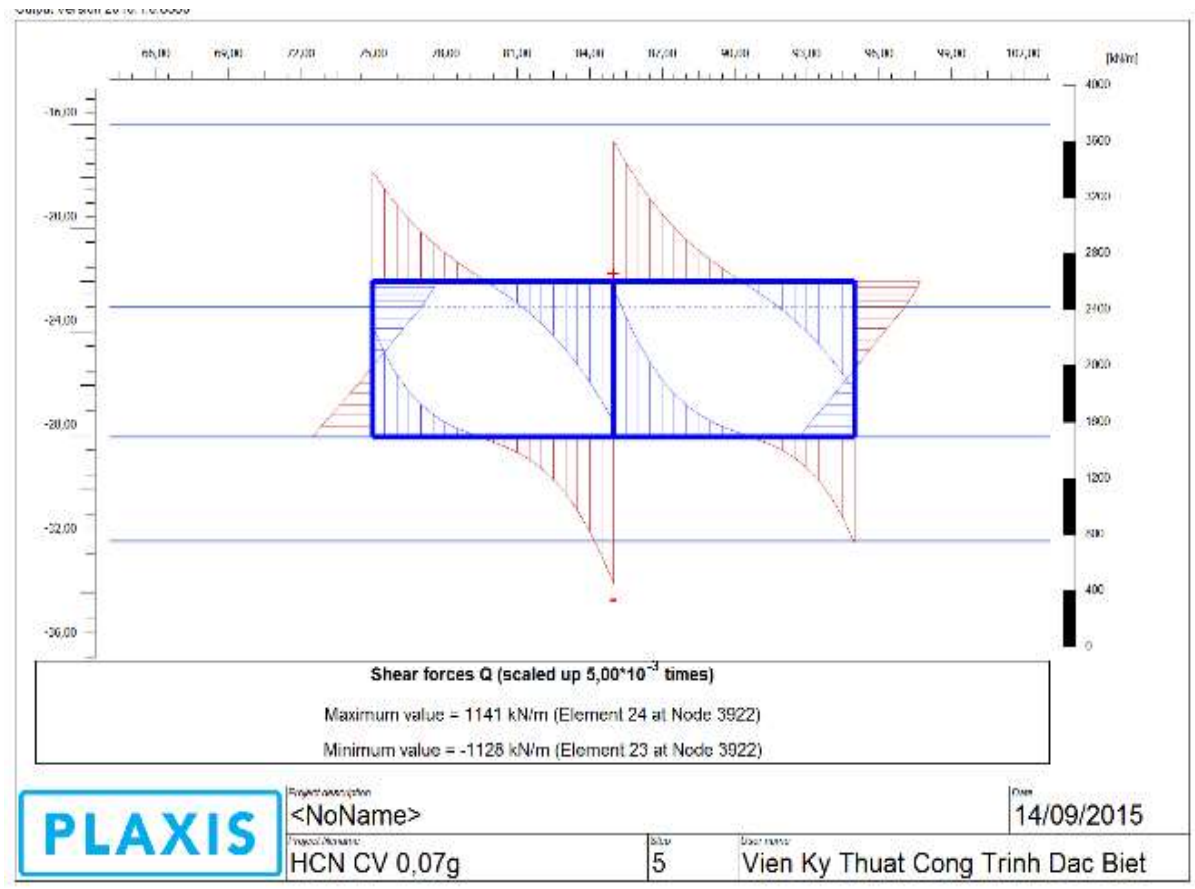

Figure 6. Shear forces of tunnel lining

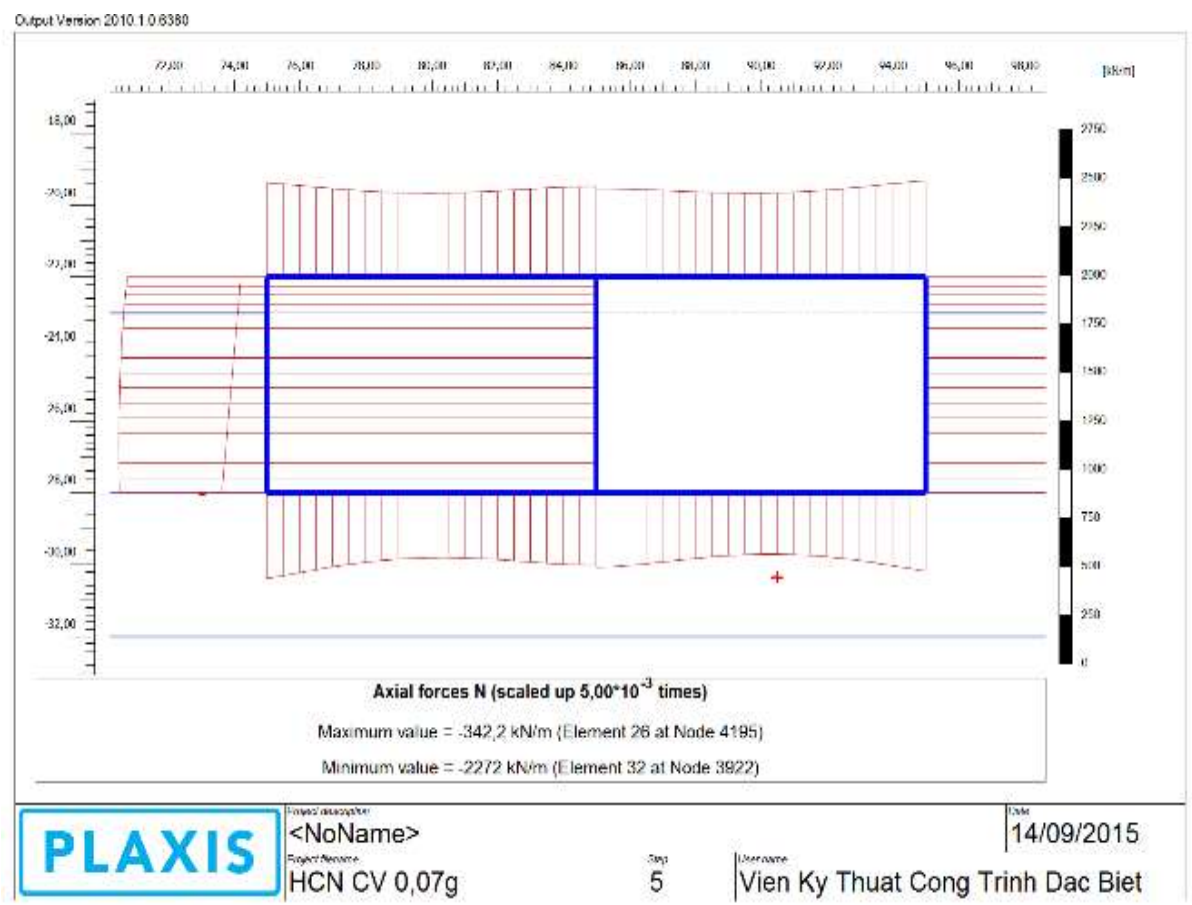

Figure 7. Axial forces of tunnel lining 


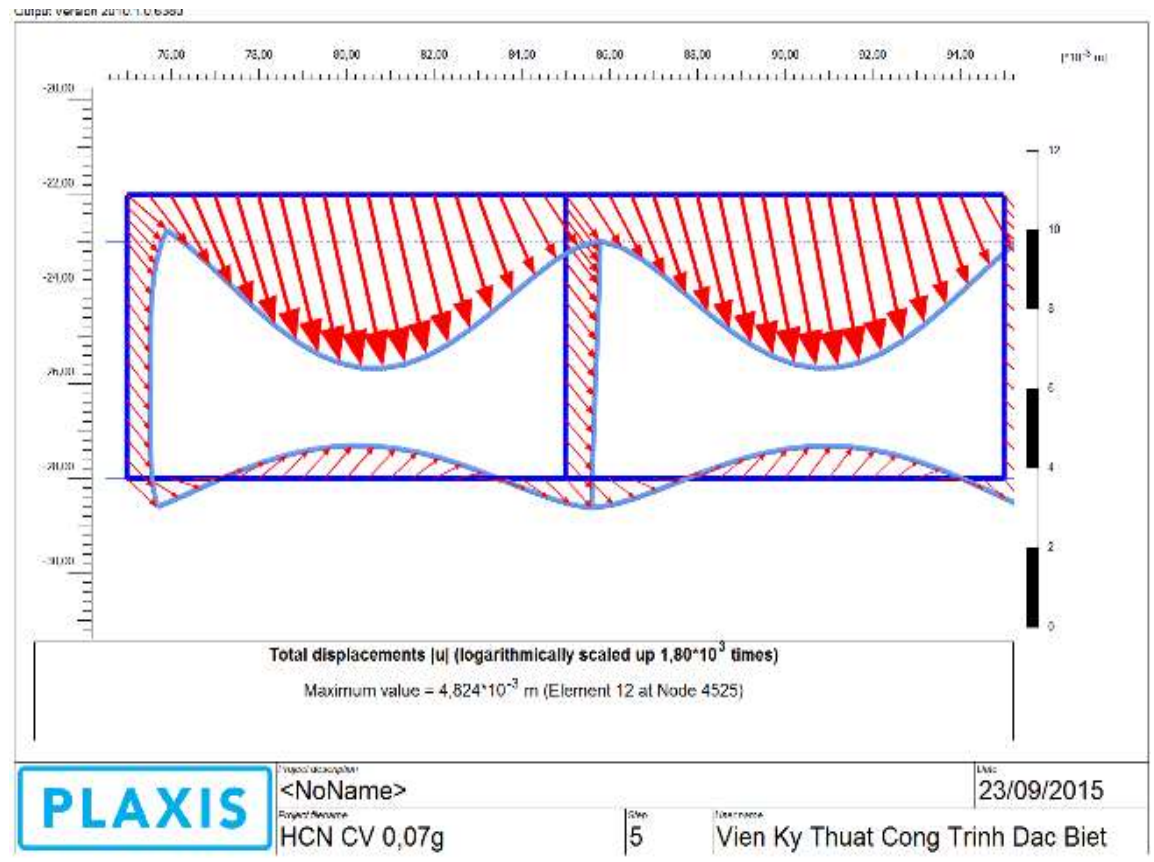

Figure 8. Total displacements of tunnel lining

\subsection{The acceleration diagram - Full dynamic method.}

\section{Initial data:}

In order to analyze the tunnel - soil model by the acceleration diagram method, there should be the accelerometer data of the design area but in fact it is difficult to have it. Therefore, the need is to create the made-up (man-made) band of the ground acceleration in order to calculate the design. Man-made acceleration diagram with can be created based on the adjustment of the real acceleration diagrams that is recorded by the global physicists at the earthquake areas which has similar characteristics of ground data as proposed designation areas with the ratio of the data area.

Using the methods of real acceleration diagram ratio to create the man-made acceleration diagram is built on the foundation that is only different from the value of respective amplitude with the same frequency. That means the amplitude of the Fourier chain of the real time function (nature) is adjusted while the phase of Fourier chain is maintained unchanged [3]. The way to create this new time function is based on the joint with the integrated response spectrum in the frequency range using the real time function in order to build the new time function that is suitable for the target response spectrum. The time function is collected in the frequency range because the response spectrum ratio with the target response spectrum. The execute process is repeated until to collect the best reaction frequency range with the target spectrum function (Fahjan và Ozdemir, 2008) [3]. The analyzed process is repeated as follows:

- Choose the real time function relative to the design area need rate;

- Identify the target response spectrum function according to the designed standard TCVN 9386:2012;

- To calculate the response spectrum function of the real time function above, we use the damping ratio of the target response spectrum function.

- The ratio between the real time function and the target response spectrum function is calculated, $\alpha$, as follows [3]:

$$
\alpha=\frac{S_{a}^{R E A L}}{S_{a}^{T A R G E T}}
$$

- Transform this ratio to the frequency domain, the amplitude of Fourier spectrum is multiple to ratio coefficient $\alpha$; 
- The new time function is identified from the Fourier spectrum multiple to the ratio and inverse Fourier transform.

Numerical modeling: Numerical simulation data are taken as for the ISGD method above.

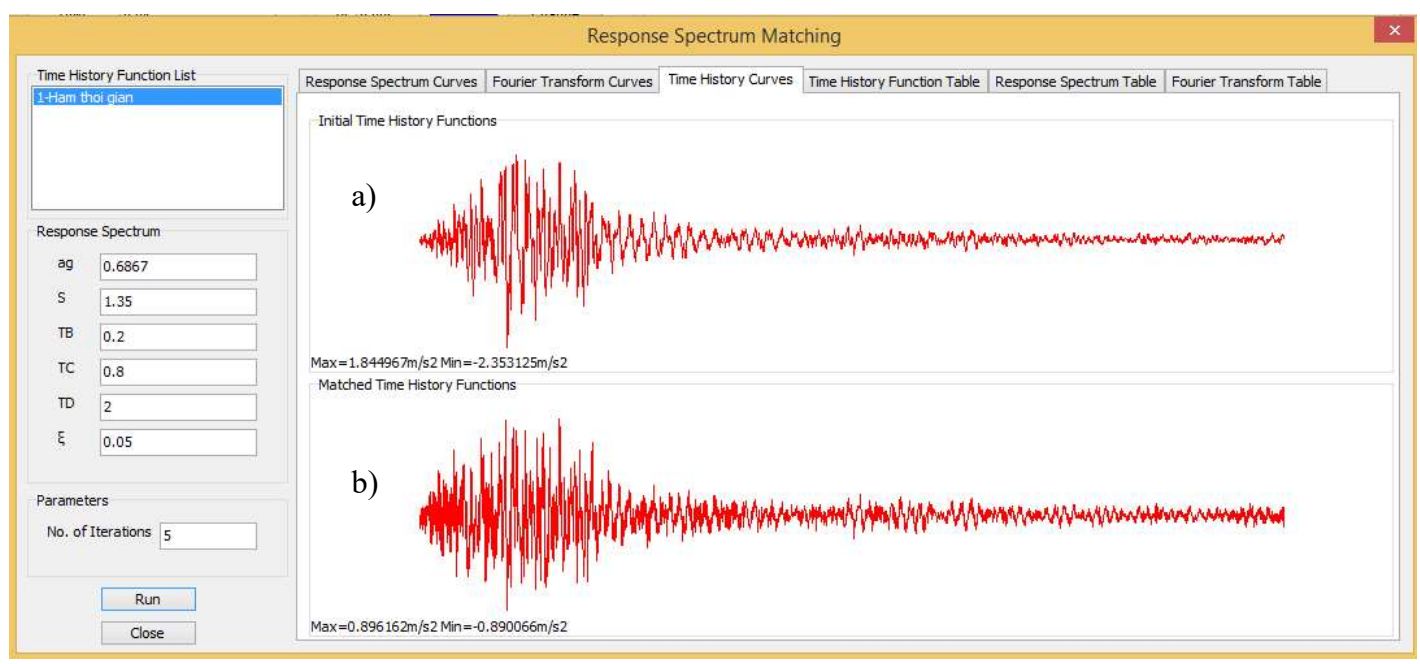

a) The real acceleration diagram; b) Artificial acceleration diagram $\left(\mathrm{a}_{\mathrm{g}}=0,07 \mathrm{~g}\right)$;

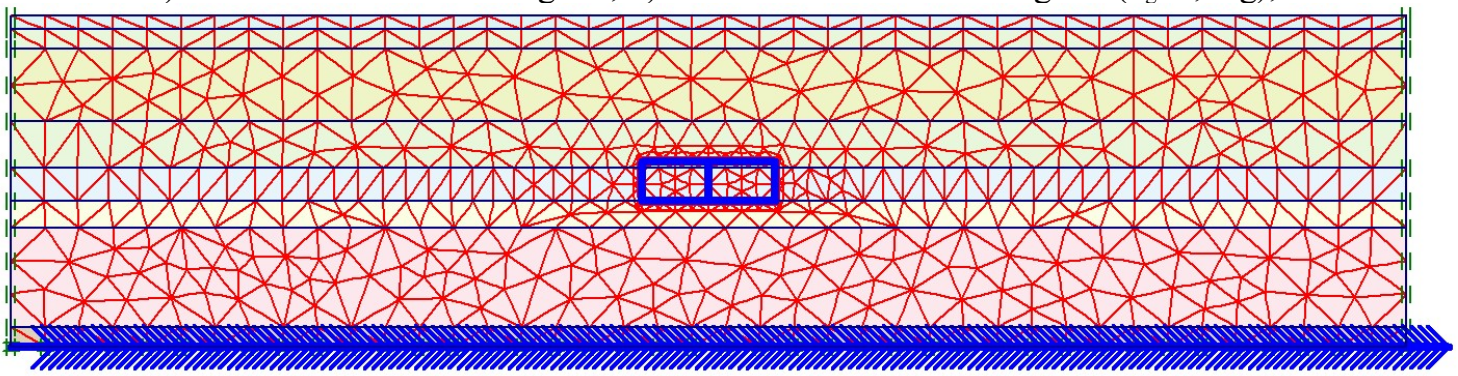

c) Finite element model in Plaxis 8.5

Figure 9.

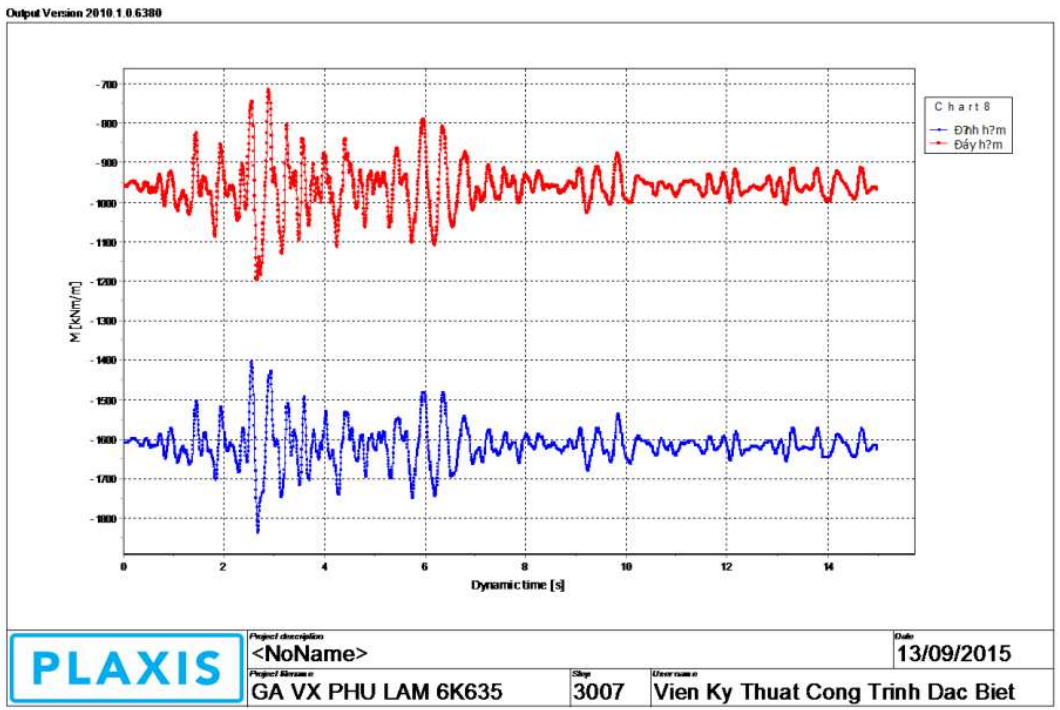

Figure 10. Bending moments at top and bottom of tunnel lining 
The results of the acceleration diagram: From the real acceleration function of the same area measured (Figure 9a), proceed to determine the artificial acceleration in the above sequence (Figure 9b) using Excel software and place it at the bottom of the computational model (Figure 9c). Perform a model analysis using Plaxis software, the internal forces - time diagram and maximum displacement of the lining was determined as shown in Figure 10 to Figure 13.

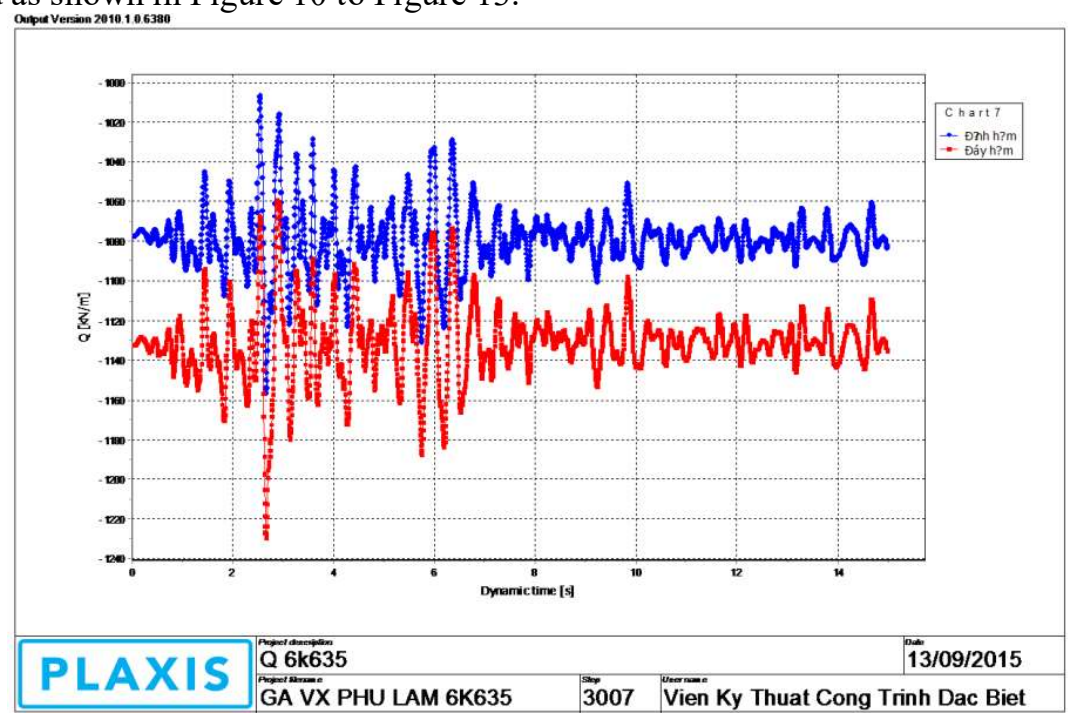

Figure 11. Shear forces at top and bottom of tunnel lining

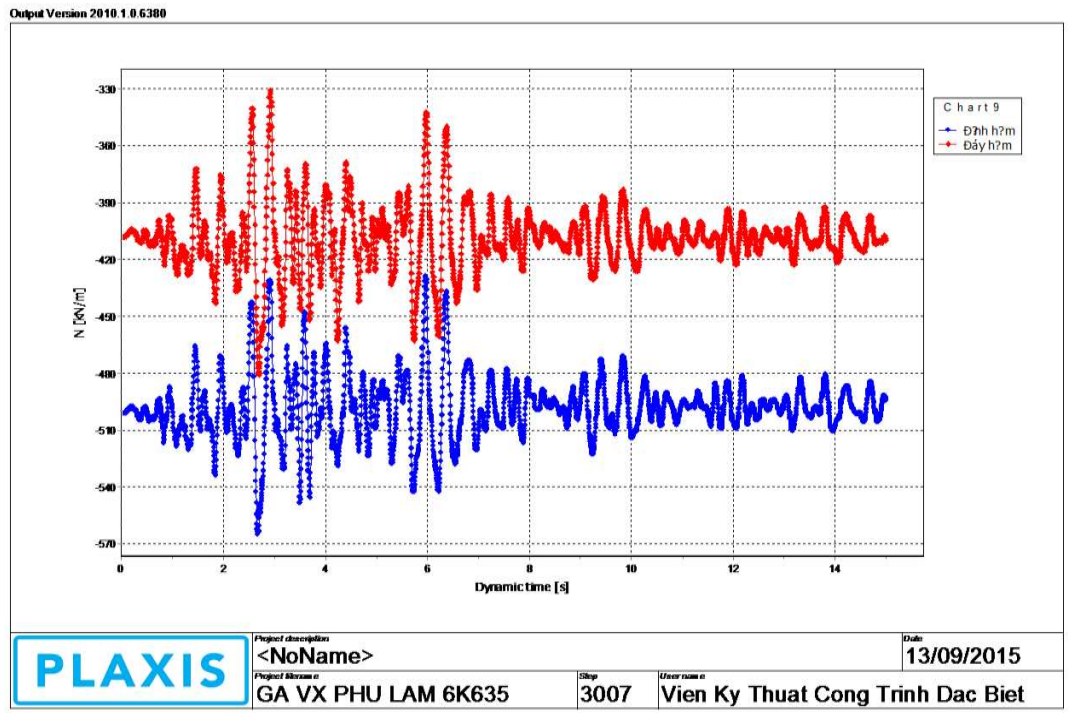

Figure 12. Axial forces top and bottom of tunnel lining 


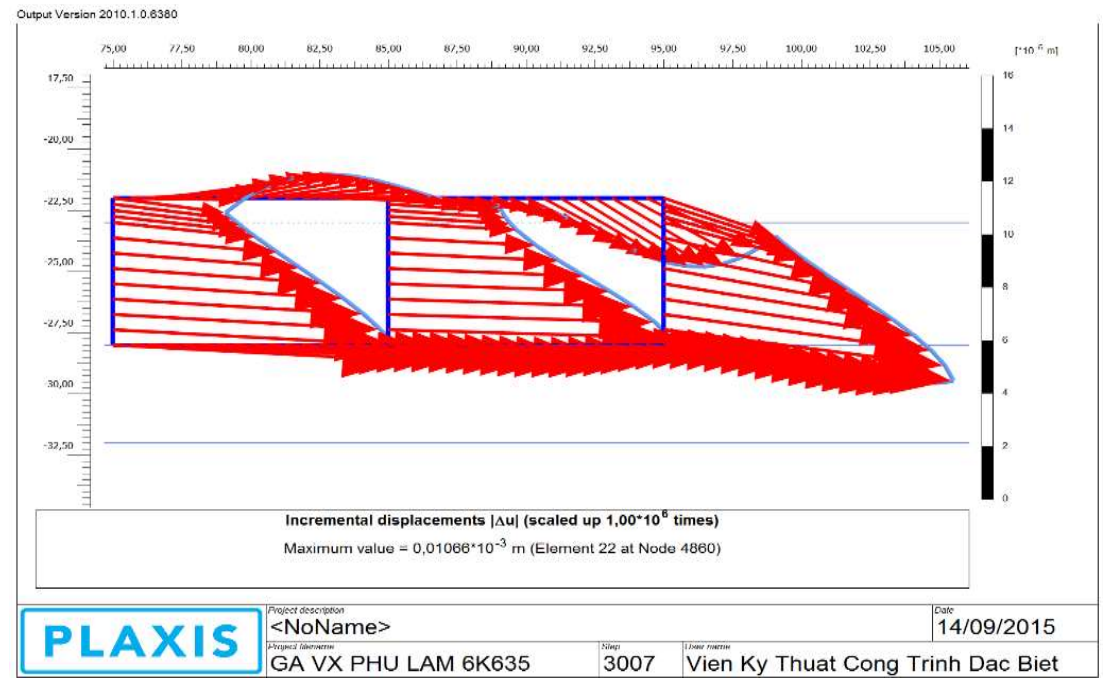

Figure 13. Total displacements of tunnel lining

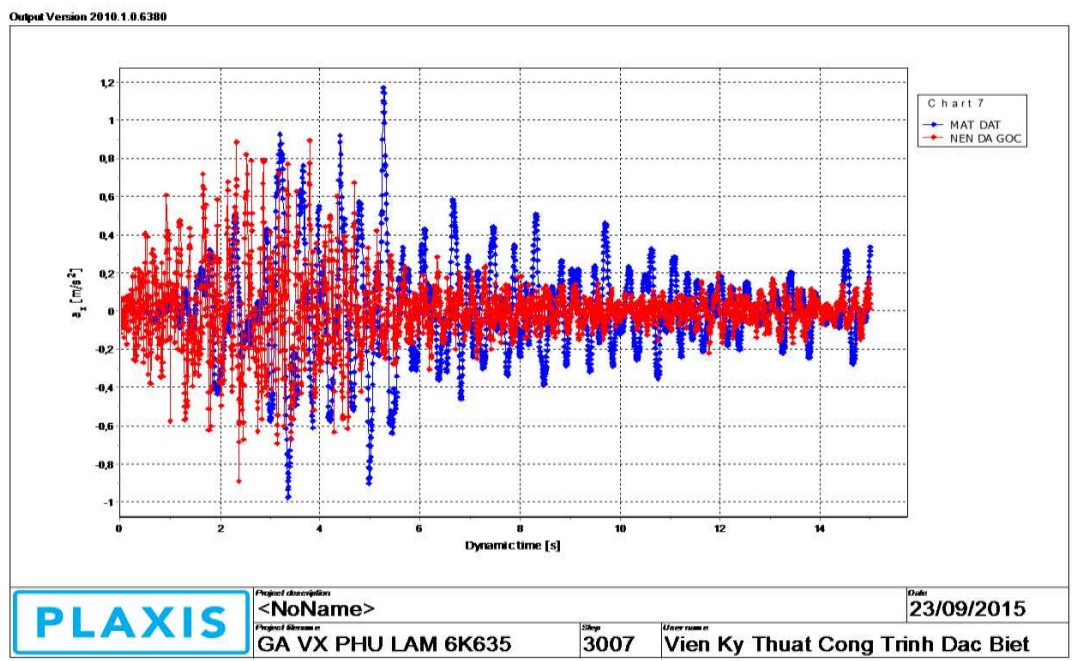

Figure 14. The acceleration at the bedrock (Blue) and on the ground (Red)

Results obtained from these two methods are presented in Table 2.

Table 2. Result internal forces in the lining.

\begin{tabular}{|c|c|c|r|r|}
\hline Analytical methods & $\begin{array}{c}\text { The Effect of sliding } \\
\text { between lining and ground }\end{array}$ & $\begin{array}{l}\mathrm{N}_{\max } \\
(\mathrm{kN})\end{array}$ & $\begin{array}{c}\mathrm{Q}_{\max } \\
(\mathrm{kN})\end{array}$ & $\begin{array}{c}\mathrm{M}_{\max } \\
(\mathrm{kN} . \mathrm{m})\end{array}$ \\
\hline \multirow{2}{*}{ The ISGD method } & No slip & $2.269,8$ & $1.138,4$ & $1.622,4$ \\
\cline { 2 - 5 } & Full slip & $2.272,4$ & $1.141,2$ & $1.634,1$ \\
\hline \multirow{2}{*}{ The full dynamic method } & No slip & $2.278,7$ & $1.146,4$ & $1.665,2$ \\
\cline { 2 - 5 } & $\mathrm{R}_{\text {int }}=0,7$ & $2.281,3$ & $1.147,9$ & $1.679,4$ \\
\hline
\end{tabular}




\section{CONCLUSIONS}

The acceleration of the ground due to earthquake is amplified in soft soil layers (figure 14), the peak acceleration at the bedrock, $a_{x}=0,858 \mathrm{~m} / \mathrm{s}^{2}$ at $\mathrm{t}=2,375 \mathrm{~s}$; on the ground surface after transfer from the bedrock at $\mathrm{t}=5,270 \mathrm{~s}$ with the peak acceleration is $\mathrm{a}_{\mathrm{x}}=1,168 \mathrm{~m} / \mathrm{s}^{2}$.

The results of calculations in the both methods are similar, however the ISGD method is the static method so cannot reflect the behavior of the underground works in term of time.

The Full dynamic method describes the behavior of the tunnel lining in term of time. In the condition cannot measure the real acceleration function, it can be created man-made ground acceleration function with the above method.

Calculating for the case of model above with the most popular laptops today, it takes about 1 hour to calculate by ISGD method while the calculation method B is 8 hours.

Recommendation: The ISGD method should be used to calculate the design in the fact to save time; The full dynamics method should be used to research and analysis behavior of the structures in term of time.

\section{REFERENCES}

[1]. Das B.M., Principles of soil dynamics, PWS-KENT Publishing Company, USA, 1995.

[2]. Fadeev A.B., Finite Element Methods in Geomechanics (translations), Education Publishing, Ha Noi, 1995.

[3]. Fahjan, Y. M., and Ozdemir, Z., Scaling of Earthquake Acceleration for Nonlinear Dynamic Analyses to Match the Earthquake Design Spectra, the $14^{\text {th }}$ World Conference on Earthquake Engineering, Beijing, China, 2008.

[4]. VietNamese Standard - TCVN 9386: 2012, Design of structures for earthquake resistances, 2012.

[5]. Xiansheng, H., Zhiliang, W. and Yimin, P., The Effect of Underlying Bedrock Topography on Earthquake Ground Motion, fifth International Conference on Numerical Methods in Geomechanics, Nagoya, 1985.

[6]. Hamada M., Izumi H., Iwano M. and Shiba Y., Analysis of dynamic strain around rock cavern and earthquake resistant design, J. of JSCE, No. 341, pp. 197-205, 1984.

[7]. Penzien, J., Seismically incluced racking of tunnel linings. Earthquake Engineering and Structural Dynamics, Vol 29, 2000.

\section{NGHIÊN CÚU SỬ LÀM VIỆC CỦA ĐƯờnG HẦM TRONG ĐẤT YẾU CHỊU TÁC DỤNG CỦA ĐỘNG ĐẤT TẠI THÀNH PHỐ HỒ CHÍ MINH}

Tóm tắt: Do nhu cầu phát triển kinh tế và hạn chế ùn tắc giao thông, Tp.HCM đã triển khai dự án đường sắt đô thị thành phố Hồ Chí Minh từ năm 2007 và hiện đang xây dựng tuyến tàu điện ngầm số 01 . Cho đến nay, các công trình ngầm nói chung và đường hầm nói riêng ở Việt Nam là một vấn đề phức tạp, đặc biệt trong điều kiện đất yếu của Thành phố Hồ Chí Minh. Để nghiên cứu ứng xử của đường hầm trong quá trình chịu động đất, bài báo trình bày so sánh Phương pháp đặt biến dạng nền cưỡng bức vào biên hay phương pháp tĩnh tương đương - ISGD và Phương pháp tính toán theo giản đồ gia tốc hay phương pháp động lực học trong tính toán đường hầm trong nền đất yếu của Tp.HCM chịu tác dụng của động đất.

Từ khóa: Phân tích động đất, kết cấu công trình ngầm, đặt biến dạng nền cưỡng bức, giả đồ gia tốc, đất yếu.

Ngày nhận bài: 29/09/2017

Ngày chấp nhận đăng: 31/12/2017 